\title{
Story Guided Virtual Environments in Educational Applications
}

\author{
Vedad Hulusic ${ }^{1}$ * and Selma Rizvic ${ }^{2}$ \\ 1 Sarajevo School of Science and Technology, \\ Sarajevo, Bosnia and Herzegovina \\ 2 Faculty of Electrical Engineering, University of Sarajevo \\ Sarajevo, Bosnia and Herzegovina
}

\begin{abstract}
Over the last few years we have witnessed a rapid development and popularisation of serious gaming. This field is becoming approved in not only education, science, medicine, religion or engineering, but also in the area of cultural heritage through serious heritage games. This can be utilised for virtual reconstructions and virtual museums and possibly used for education in the form of edutainment, comprising various techniques, such as storytelling, visual expression of information, interactivity and entertainment [19]. This paper demonstrates a new concept of using story guided virtual environments for cultural heritage virtual reconstruction, with live virtual guides in an interactive Flash format. First we compare the implementations of the same environments in $\mathrm{x} 3 \mathrm{D}$ and Flash and then we extend the project with digital storytelling, where a user is guided through the whole application using both narrative, non-interactive, movie-like elements and interactive exploration of the virtual environment. The introduced results can be easily adopted for serious games development.
\end{abstract}

Keywords: cultural heritage, virtual reconstruction, live virtual guides, digital storytelling, interactive digital stories

\section{Introduction}

For many years, games were considered only as an entertainment medium. However, serious gaming introduced several new aspects of gaming, including education, health training, scientific simulations, historical presentations, etc. Serious games, such as Microsoft Flight Simulator or Global Conflict: Palestine, can offer the same type of gameplay as commercial off-the-shelf games, or they can have different type of interaction and presentation, such as Houthoff Buruma - The Game.

One subcategory of serious games are serious heritage games [19]. These games involve cultural heritage objects or sites, usually in a form of virtual reconstructions or virtual museums. The former is typically used either for rebuilding non-existing objects or sites, or for digital 2D or 3D representation of

\footnotetext{
^vedad.hulusic@ssst.edu.ba
} 
an important existing object or site. The latter is used for popularisation of real museums providing world wide availability via internet or for allowing better examination of artefacts that are for example prohibited from touching. Additionally, in this type of environments, avatars or virtual guides may be employed for storytelling, which enhances the user experience by providing a higher level of immersion and presenting the important information in a narrative form.

In this paper we present a novel way of combining live virtual guides with computer generated heritage sites within Flash environment. The application is optimised for web presentations and does not require any additional software installations. Furthermore, this concept allows offline rendering. Since, even on the high-end machines it is still not possible to perform physically-based rendering at satisfactory interactive frame rates, our concept enables us to pre-render images using physically-based rendering at no cost for the user.

The paper is organised as follows: in Section 2 we give an overview of the work done so far on virtual reconstructions, virtual museums, digital storytelling and virtual guides; Section 3 briefly describes the project of the virtual reconstruction of the Church of the Holy Trinity in Mostar; in Section 4 the creation of the virtual environment in Flash is described; in Section 5 the pilot user study comparing Flash and X3D implementations is presented; Section 6 explains the proposed concept of story guided virtual environments, presents the initial user feedback and discusses potential utilisation of the concept in serious games; and finally, the conclusions and the future work are given in section 7 .

\section{Related work}

Virtual Reality(VR) environments, as we know it today, have been used for almost half a century, starting with the Morton Heilig's Sensorama in 1962, which is considered to be the first immersive, multi-sensory device. With the advancement of the technology and computing algorithms, the VR field progressed, producing more realistic and interactive environments and applications, such as $[26,30,41]$. However, these advances may not be satisfactory for conveying information to the user. This means that, although the virtual environment may be highly realistic and immersive, important information might not reach users in an understandable and desired way. An efficient way of teaching, instructing or informing users about some objects, events, facts or people is using digital storytelling $[21,32]$. This technique helps involve the audience as active participants and drives the development of a plot.

\subsection{Virtual reconstruction of cultural heritage}

Virtual reconstruction of cultural heritage sites is extremely important for preservation and presentation of both non-existing and existing historical sites and stories, culture, architecture, customs and moral values. There are numerous examples of virtual reconstructions of different historical sites from all around the world $[24,40,22,28,23,37,25,35]$. Another type of promotion and preservation 
of cultural heritage is the creation of virtual museums $[9,8,7,6,3,2,13,14,16$, $15,18,17,12,11,10]$. Virtual museums allow remote visitors to experience and explore the museums using web presentations, attract potential visitors to visit the real museums and inform the visitors in the actual museums what they can see in the museum. It also provides a detailed exploration of some preserved artefacts which had to be conserved.

\section{$2.2 \quad$ Virtual guides}

There are multiple forms of conveying information to a user, such as text, audio, video, animated 3D characters, real or virtual avatars, etc. The results from a user study by Sadzak et al. showed that live virtual guides are more effective and preferable for users than computer generated virtual guides. [39]. Furthermore, forms of storytelling have been proven as a good concept for information conveyance in virtual environments $[38,36]$. Therefore, in this paper we used digital storytelling performed by a live virtual guide, in order to tell a user the stories about the reconstructed object and its important elements.

\section{Virtual reconstruction of the Church of the Holy Trinity in Mostar}
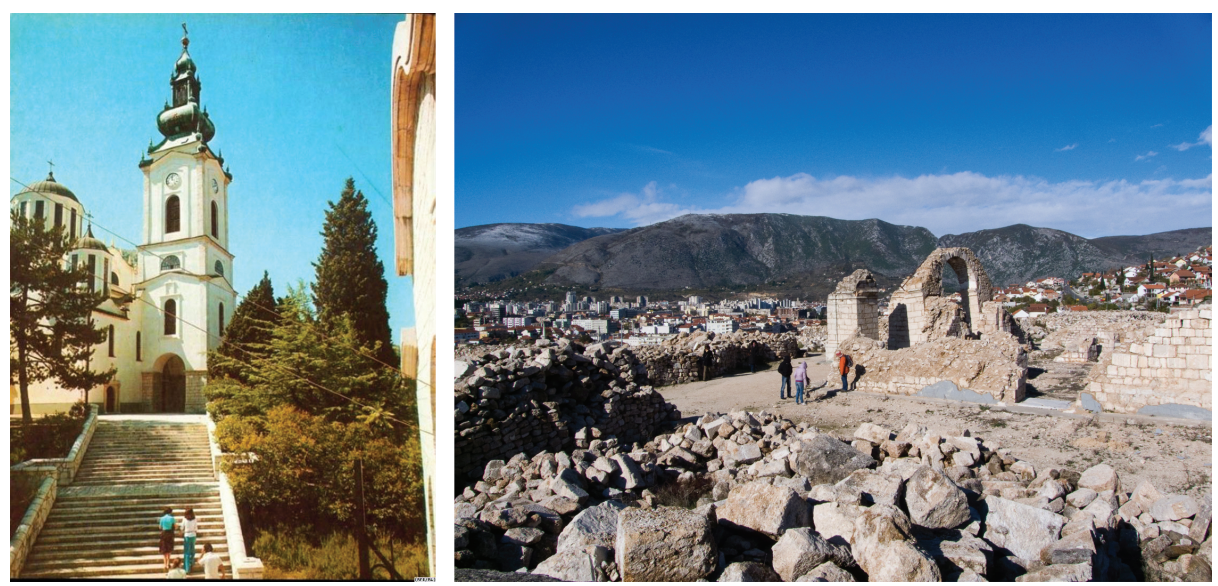

Fig. 1. The church before (left) and after the destruction (right).

The Church of the Holy Trinity in Mostar (Figure 1) was one of the most important and most significant religious and cultural objects in Bosnia and Herzegovina and the Balkans. This Orthodox church was completely destroyed in 1992, during the war in Bosnia and Herzegovina. In order to promote its beauty and 
significance, as well as to encourage its physical reconstruction, a virtual reconstruction has been done [31], see Figure 2. The project of virtual reconstruction included: creating 3D models of the church interior and exterior; capturing the High Dynamic Range (HDR) panoramic photograph of the church environment; developing a web and offline presentation with historical information, photo gallery, video of the church devastation, X3D interactive virtual model and a digital story with live virtual guides; and printing a 3D prototype of the model [35]. The project aroused significant media attention and the Orthodox religious community was very pleased with the results.
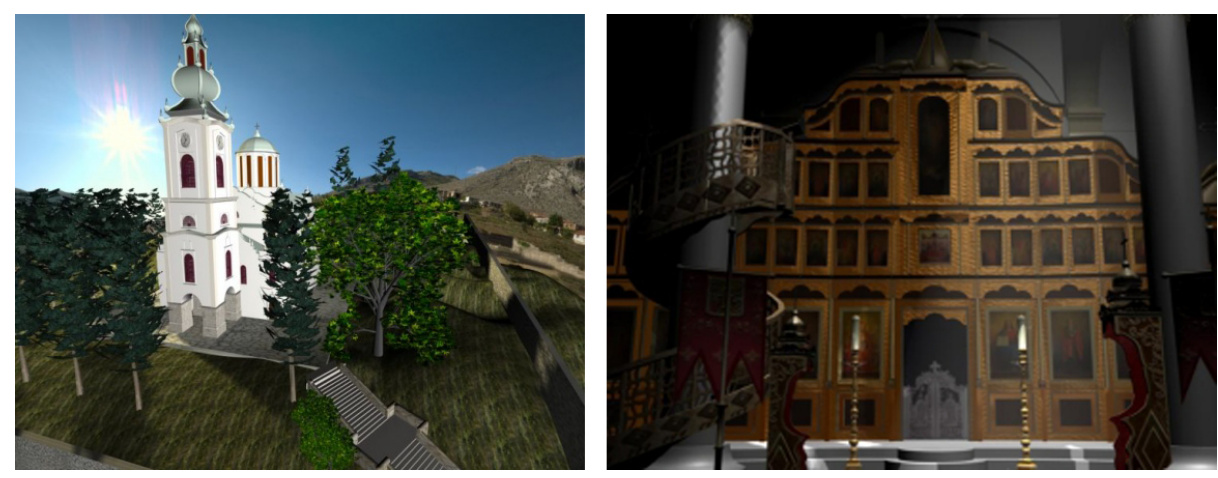

Fig. 2. Rendered images of the virtually reconstructed church: exterior (left) and interior (right).

Table 1. The comparison of the data size and download time for the X3D and our concept (Flash). The download speed used for the measurement was 3Mbps.

\begin{tabular}{|c||c|c|c|c|c|}
\hline \multicolumn{1}{|c||}{} & \multicolumn{2}{c|}{ Outdoor } & \multicolumn{2}{c|}{ Indoor } & Outdoor + Indoor \\
\hline & Total size & Initial size & Total size & Initial size & Total \\
\hline X3D & $58 \mathrm{MB}$ & $32 \mathrm{MB}$ & $45 \mathrm{MB}$ & $28.8 \mathrm{MB}$ & $103 \mathrm{MB}$ \\
(download time) & $(155 \mathrm{~s})$ & $(85 \mathrm{~s})$ & $(120 \mathrm{~s})$ & $(77 \mathrm{~s})$ & $(275 \mathrm{~s})$ \\
\hline Flash & $5.6 \mathrm{MB}$ & $5.6 \mathrm{MB}$ & $5.1 \mathrm{MB}$ & $5.1 \mathrm{MB}$ & $10.7 \mathrm{MB}$ \\
(download time) & $(15 \mathrm{~s})$ & $(15 \mathrm{~s})$ & $(14 \mathrm{~s})$ & $(14 \mathrm{~s})$ & $(29 \mathrm{~s})$ \\
\hline
\end{tabular}

However, there were a couple of drawbacks in the project. The first one was its data size. This is particularly considerable in countries with lower internet speeds, such as Bosnia and Herzegovina. Table 1 shows the model size and the download times, both for the outdoor and indoor part of the model. Although the 3D model was partially optimised, the geometry could be further optimised using polygon reduction methods. However, this process usually requires sig- 
nificant amount of time, as it can not be fully automated. Furthermore, the geometry itself might not be suitable for optimisation (holes in the objects, nonmanifold geometry, duplicated and overlapping vetrices, edges or faces, etc.), which, therefore, requires geometry clean-up and reconstruction.
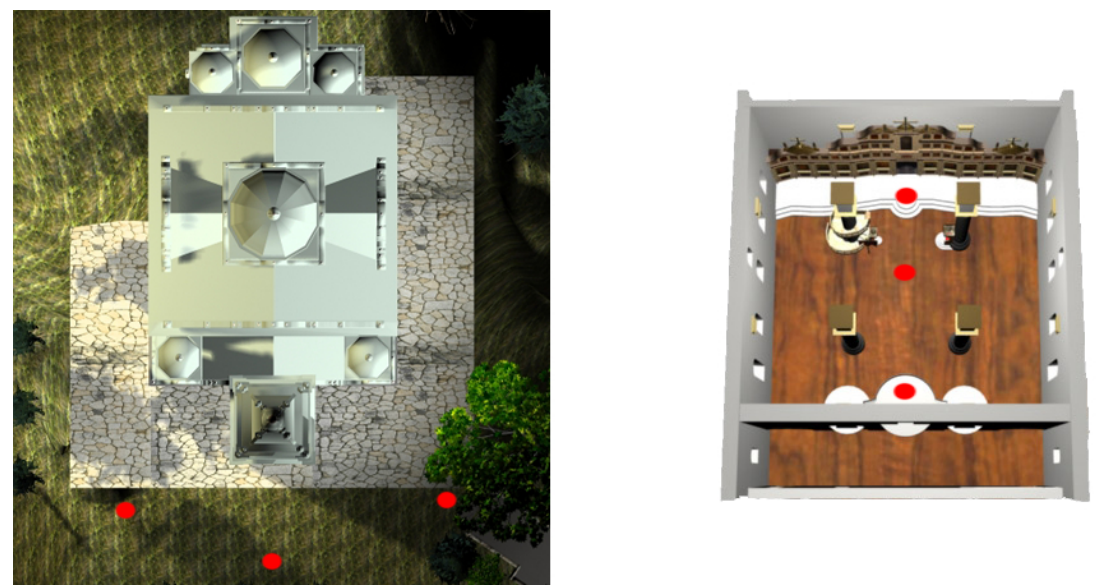

Fig. 3. The rendering view points outdoors(left) and indoors(right) marked with the red dots.

The second drawback is the software requirement. Namely, a user has to install X3D player or browser plug-in for viewing the model. This is not very popular amongst internet users, as it consumes time, requires certain level of computer literacy and represents a security risk, as the user can not be sure if the program could harm his or her machine.

\section{Creating the virtual environment in Flash}

In order to improve the performance of the virtual environment, another approach was employed. Instead of exporting the 3D model to X3D, the panoramic images were rendered directly from Autodesk Maya, using the MentalRay renderer. Since Maya does not provide a panoramic lens by default, the latlong lens MentalRay lens shader was downloaded and used [29]. The shader enables a full $360 / 180$ rendering of a scene in latitude/longitude format. We decided to render the indoor and outdoor scenes at three view points each, see Figure 3. During the scene set up, it was possible to further improve the appearance of the scene by adjusting the geometry, lights and materials. However, we tried to make as little intervention on the 3D model as possible.

The virtual guide was recorded against a green screen background and keyed out with the alpha channel using the Keylight plug-in in Adobe After Effects 
CS5, see Figure 4. The output was saved as a lossless Quicktime movie and then recoded into Flash (.swf) format using Adobe Media Encoder CS5.

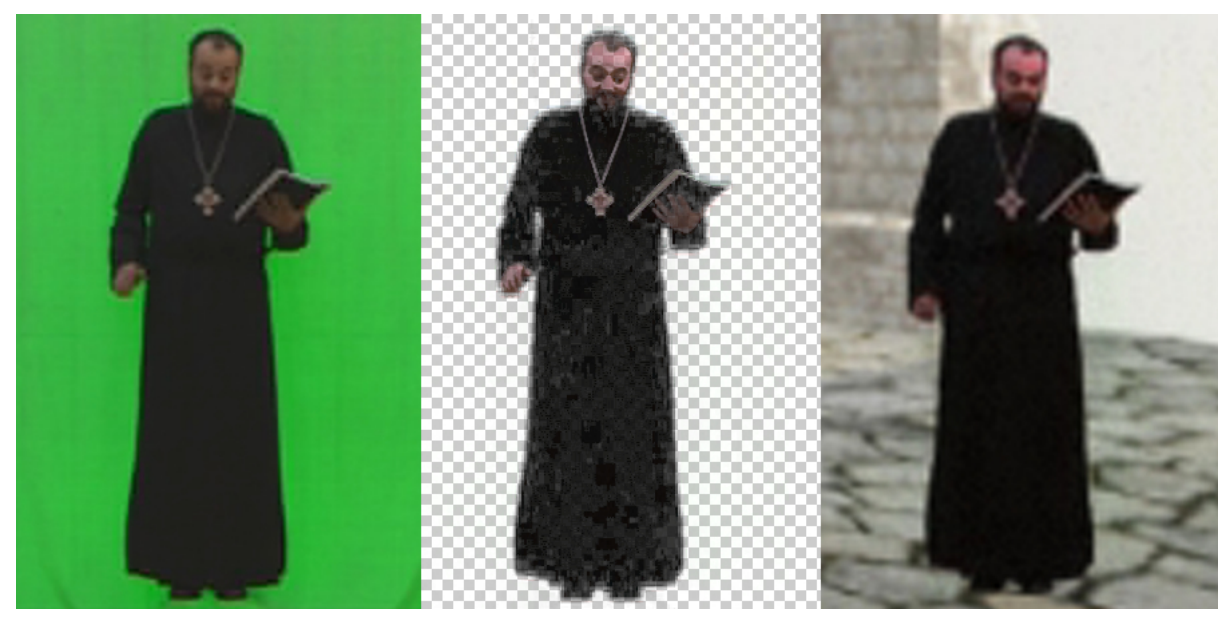

Fig. 4. Keying the footage: virtual guide against the green screen (left); virtual guide keyed out with alpha channel (middle); virtual guide superimposed on the virtual model (right).

For the virtual environment and user interface Tourweaver 5.00 Professional Edition was used. This software allowed us to merge the prepared images, create navigation, embed virtual guides and export it for both stand-alone (executable) and web presentation (Flash). We started with a blank new project, and imported the images as scenes. Then, on corresponding scenes we added Flash Media and chose the virtual guide, see Figure 5.

In the next step we added the Map Viewer and assigned it the image of the map. On each map the Radar Hotspots were set up, see Figure 3. For easier navigation, i.e. moving across the view points, Thumbnails were added at the bottom of the screen. There were three thumbnails, one for each view point, on both interior and exterior model. The final application looked as in Figure 6.

The last step in the process was to export i.e. publish the environment. Publishing options offer Flash VR and Flash VR(exe) type of exportation. The data size and the corresponding download times of the indoor and outdoor models are given in Table 1.

\section{User study: X3D vs. Flash}

As shown in Section 3, using our method the data size was decreased around ten times, which speeds up the loading process dramatically. This factor might be 


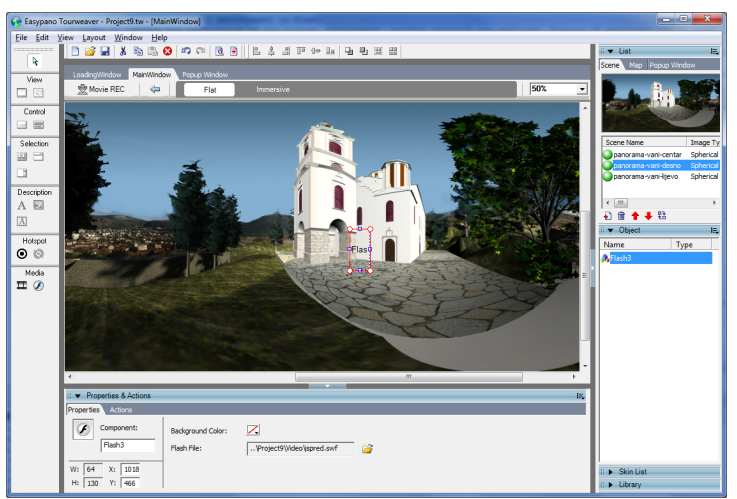

Fig. 5. The process of creating the virtual environment.

significant, particularly for users with lower internet speeds. In order to compare how the users perceive two environments - the X3D and Flash, we made a pilot user study with 10 participants. There were 5 male and 5 female participants, aged from 24 to 43, with an average of 30. All of them had normal or corrected to normal vision and no hearing impairments. The participants were sent the instructions and the questionnaire by email. They were asked to send the questionnaire back upon completion. All participants reported to have broadband connection with varying download and upload speeds. Two participants, one male and one female, reported that they could not run the X3D environment. This might be due to low download speed (one of the two participants reported bandwidth of $512 / 256$ bps) or some other technical issues such as firewall. These two participants were excluded from the results evaluation.
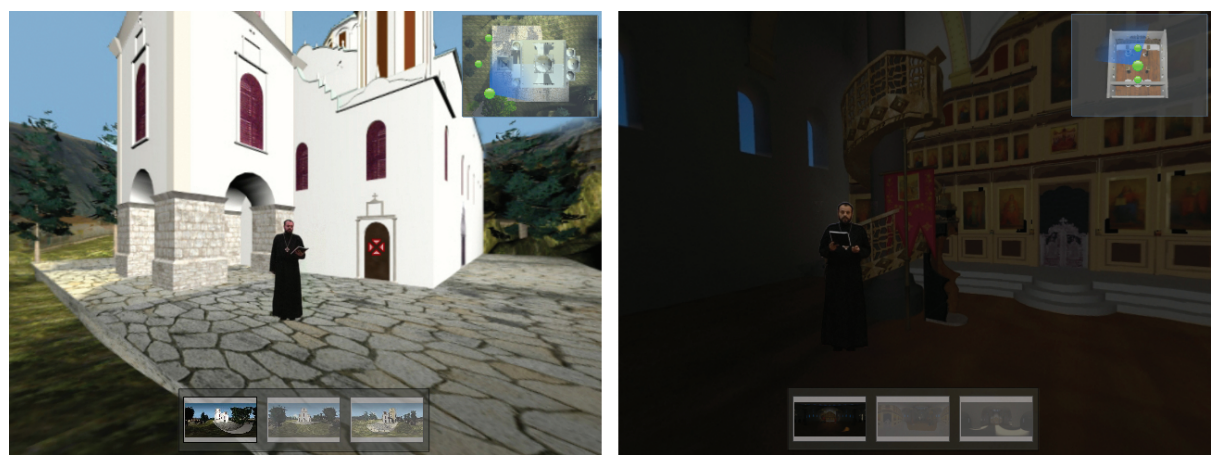

Fig. 6. The exterior (left) and interior (right) of the virtual environment. 
The results gained from the pilot study are presented in Table 2 . There we can see that the users were more satisfied with the Flash implementation, comparing to X3D. They reported higher loading speed, better navigation, graphics and virtual guides in the Flash application. Additionally, $50 \%$ of the participants stated that they do not mind installing new software and $50 \%$ prefer not to install any new software. Nevertheless, some users expressed concerns regarding the freedom of navigation, stating that the x3D environment offers better browsing possibilities.

Although, the pilot study was conducted with a small sample size, and therefore does not provide a statistically significant evidence, the results represent a good indication of the potential of using live virtual guides in Flash environment for cultural heritage virtual reconstruction.

Table 2. The results from the pilot user study, showing the number of given answers.

\begin{tabular}{|l|c|c|}
\hline Question & X3D & Flash \\
\hline Which application loads faster? & 0 & 8 \\
\hline Which application is easier to navigate through (explore the environment)? & 1 & 7 \\
\hline Which application has better graphics (looks better)? & 1 & 7 \\
\hline What virtual guide (avatar) did you prefer? & 1 & 7 \\
\hline Which application do you prefer in overall? & 0 & 8 \\
\hline How did you feel about installing new software onto your machine: & & \\
- I like installing new software & \multicolumn{2}{|c|}{0} \\
- I do not mind installing new software & \multicolumn{2}{|c|}{4} \\
- I prefer not to install new software & \multicolumn{2}{|c|}{4} \\
- I never install any new software & \multicolumn{2}{|c|}{0} \\
\hline
\end{tabular}

\section{Story guided virtual environment}

Since the user study presented in Section 5 showed a high potential of our approach, we decided to enrich the environment, and thus user experience, introducing more elements of digital storytelling.

\subsection{Concept and Implementation}

By now, the presentation of the project consisted of several elements: textual information about the church (history and revival); an image gallery; a video of the church destruction; an interactive model; and a digital story [1]. Each of these elements are accessible at different locations (web pages) on the web site. Therefore, it is not guarantied that a user will visit them all and from all those various types of information be able to understand, or feel the whole story. 

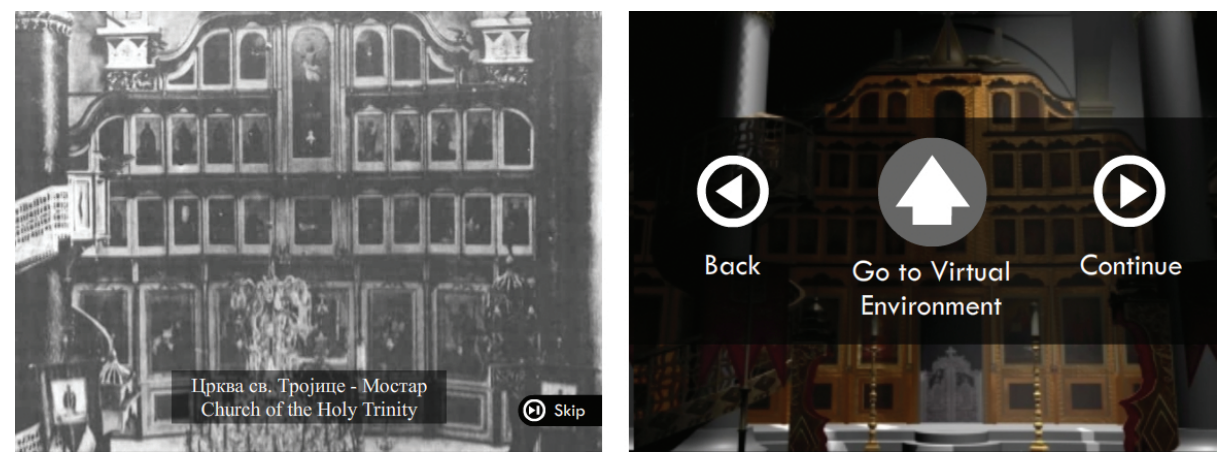

Fig. 7. Controls for navigating through the virtual environment. Skip button (left) for moving to the end of the story part being played, and the choice menu (right) presented at the end of the story parts.

Therefore, a different concept, similar to the one proposed by the same group of authors in the Sarajevo Survival Tools project [4] (the article is in the process of submission) was utilised. This concept incorporates all the mentioned information presentation styles into one story guided virtual environment [5]. The expanded digital story guides a user through the environment, allowing him or her to interactively explore certain features and listen to the stories told by a live virtual guide.

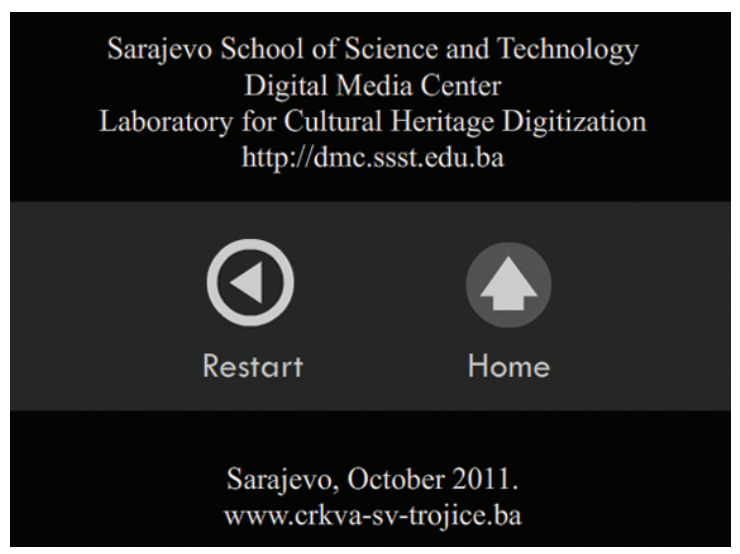

Fig. 8. A screenshot of the last screen of the digital story. A user can press one of the two buttons: Restart or Home.

The digital stories were created and edited with Adobe Premiere Pro CS5 software, using digital storytelling techniques introduced in [36]. The stories were 
then imported into Adobe Flash Professional CS5 and the controls were added, see Figure 7. During each of the three parts of the digital story, a user can skip to the end by pressing the skip button. This is introduced in case the user is exploring the project several times and does not want to listen to the same story part again. Once finished or skipped, a user is given a choice: to play that part of the story again (Back button), to go to the virtual environment or the move on with the story (Continue button). At the end of the last part of the story, a user is provided with two options: to restart the whole story or to go to the project home page, see Figure 8 .

Finally, an image link (Continue button) to the next part of the digital story was added to both virtual environments (indoor and outdoor), see figure 9 . This way a user was enabled to go through the whole story guided virtual environment and experience it via different presentation media.
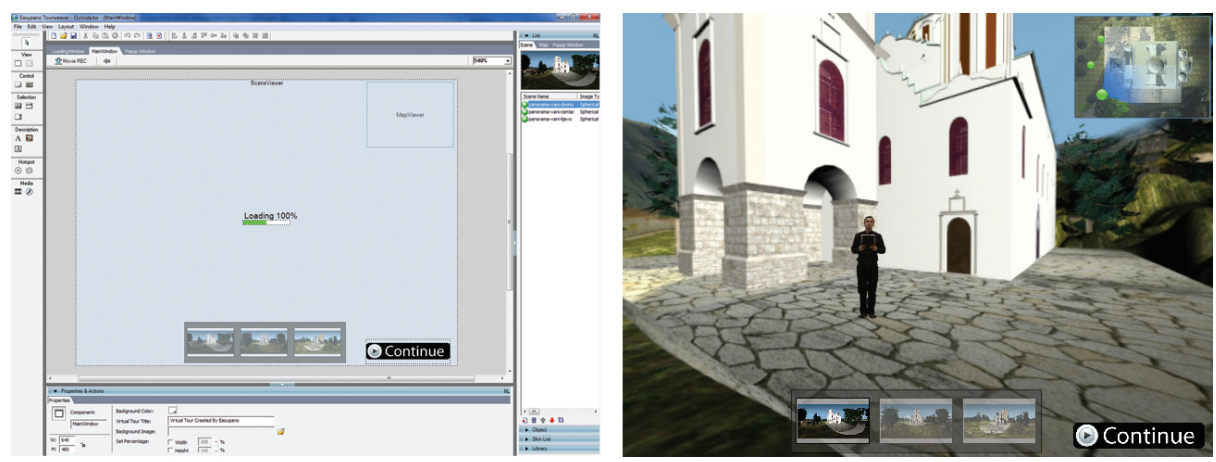

Fig. 9. Screenshots of the virtual environment exterior: development (left) and execution (right).

\subsection{Initial user feedback}

In this section, the experimental design, data collection, coding and data analysis are presented. Additionally, some initial findings and ideas for potential upgrade of the system for a serious game discussed.

Experimental design Since practice has shown that 7 users will find approximately $80 \%$ of problems of an interface [33], a single project study was conducted. This is an in-depth qualitative user study, in which certain attributes are examined and possibly compared to some organizational baseline [20]. There were 9 participants, 7 male and 2 female. They aged from 25 to 68, with an average of 39. All of them reported normal or corrected to normal vision and one participant reported some hearing impairments. Therefore, the participant was 
excluded from the study. All the other participants reported no hearing impairments. There were two criteria for selecting participants: that they are foreigners (non-Bosnians) living outside Bosnia; and that they do not know anything about the church object.

Data collection and coding For the data collection, a semi-structured questionnaire, which includes both open-ended and specific questions (see Table 3), was created and sent to the participants by email, along with the instructions document. They were asked to read the instructions, explore the story guided virtual environment, fill in the questionnaire and send back their responses.

In order to perform quantitative data analysis, data coding is necessary. This is a process of extracting qualitative data into quantitative form. In such a process the possible values of the quantitative data are created according to the given answers. Since participants often use different terms for the same phenomenon or same words for different phenomenon, it is important to perform coding as accurate as possible. In addition, one should be cautious not to lose too much information in this process.

Data analysis The data analysis was performed in two steps: defining the hypotheses and grounding the evidence. The hypotheses were generated using the constant comparison method [27]. After coding the questions, each of them representing a particular section, we went through the data looking for patterns. From the data we built several hypotheses:

- Our concept is highly effective in conveying information about the object, providing an interesting medium for education and a good platform for edutainment;

- Our concept provides high level of enjoyment despite the nature of the presentation and evoked emotions;

- Our concept is highly important and useful for reviving the memory of the non-existing objects and attracting the visitors to the heritage site.

The aim of this study is not to prove our hypothesis, but to build up the weight of evidence supporting these propositions, that could be used as ground theories in future studies. Most of the users answered correctly on the questions related to the digital story (IP1, IP2, IP4, IP5). The reason for not having higher rate of correct answers might be the limitation of the short-term memory in humans [34]. Therefore, there were several answers "Don't remember" (IP2, IP3, IP4, IP5). Additionally, in some countries a term "pulpit" is used for "amvon", which could have affected the performance on this question (IP3). However, the overall rate of correct answers, presented in Table 4, represents a rather strong evidence for the first hypothesis. 
Table 3. The questions, codes and possible values used in the study.

\begin{tabular}{|c|c|c|}
\hline Question & Code & $\begin{array}{l}\text { Possible } \\
\text { value }\end{array}$ \\
\hline Information perception & $I P$ & \\
\hline $\begin{array}{l}\text { Does the Church of the Holy Trinity still exist in } \\
\text { Mostar? }\end{array}$ & IP1 & $\begin{array}{l}\text { Correct } \\
\text { Incorrect }\end{array}$ \\
\hline Who is Spasoje Vulic? & IP2 & $\begin{array}{l}\text { Correct } \\
\text { Incorrect }\end{array}$ \\
\hline What is an amvon? & IP3 & $\begin{array}{l}\text { Correct } \\
\text { Incorrect }\end{array}$ \\
\hline Who contributed to the building of the Church? & IP4 & $\begin{array}{l}\text { Correct } \\
\text { Incorrect }\end{array}$ \\
\hline $\begin{array}{l}\text { Which church was used as a reference in virtual } \\
\text { reconstruction? }\end{array}$ & IP5 & $\begin{array}{l}\text { Correct } \\
\text { Incorrect }\end{array}$ \\
\hline Immersion & $I M$ & \\
\hline $\begin{array}{l}\text { What do you thing of the length of the interac- } \\
\text { tive digital story? Is it too long, too short or long } \\
\text { enough? }\end{array}$ & IM1-length & $\begin{array}{l}\text { short } \\
\text { good } \\
\text { long }\end{array}$ \\
\hline $\begin{array}{l}\text { Have you experienced any problems with naviga- } \\
\text { tion in the virtual environments (if yes, please de- } \\
\text { scribe)? }\end{array}$ & IM2-navigation & $\begin{array}{l}\text { good } \\
\text { average } \\
\text { bad }\end{array}$ \\
\hline Presence & $P$ & \\
\hline $\begin{array}{l}\text { Have you had a sense that you are really visit- } \\
\text { ing the church, while exploring the virtual envi- } \\
\text { ronment? Please explain why have (have not) you } \\
\text { had that feeling? }\end{array}$ & $\begin{array}{l}\text { P1-overall feeling of } \\
\text { presence }\end{array}$ & $\begin{array}{l}\text { Low } \\
\text { Average } \\
\text { High }\end{array}$ \\
\hline $\begin{array}{l}\text { In which environment you felt more present, exte- } \\
\text { rior or interior? }\end{array}$ & $\begin{array}{l}\text { P2-more presence } \\
\text { int/ext }\end{array}$ & $\begin{array}{l}\text { Interior } \\
\text { Exterior } \\
\text { both }\end{array}$ \\
\hline $\begin{array}{l}\text { Have you felt that the objects are real? Please ex- } \\
\text { plain why? }\end{array}$ & P3-realism & $\begin{array}{l}\text { Very high } \\
\text { High } \\
\text { Low }\end{array}$ \\
\hline Involvement & $I N$ & \\
\hline $\begin{array}{l}\text { What kind of emotions did you feel after watching } \\
\text { the interactive digital story? }\end{array}$ & IN1-emotions & \\
\hline Did you enjoy yourself? & IN2-enjoyment & $\begin{array}{l}\text { High } \\
\text { Low }\end{array}$ \\
\hline $\begin{array}{l}\text { Have you felt involved in the story? Please explain } \\
\text { why? }\end{array}$ & $\begin{array}{l}\text { IN3-overall in- } \\
\text { volvement }\end{array}$ & $\begin{array}{l}\text { High } \\
\text { Average } \\
\text { Low }\end{array}$ \\
\hline $\begin{array}{l}\text { Do you think that virtual guides contributed in } \\
\text { your involvement in the story (if yes, why)? }\end{array}$ & IN4-virtual guides & $\begin{array}{l}\text { Yes } \\
\text { No }\end{array}$ \\
\hline $\begin{array}{l}\text { How would you characterize the interactive digital } \\
\text { story you have seen (boring, interesting, sad, other } \\
\text { please explain)? }\end{array}$ & IN5-interestedness & $\begin{array}{l}\text { High } \\
\text { Low }\end{array}$ \\
\hline Impressions & $I M P$ & \\
\hline What is your overall impression on the project? & $\begin{array}{l}\text { IMP1-overall } \\
\text { impression }\end{array}$ & $\begin{array}{l}\text { Very bad } \\
\text { Bad } \\
\text { Good } \\
\text { Very good }\end{array}$ \\
\hline Do you think this project is useful and why? & IMP2-usefulness & $\begin{array}{l}\text { High } \\
\text { Low }\end{array}$ \\
\hline Do you wish to visit the site in reality? & IMP3-wish to visit & $\begin{array}{l}\text { No } \\
\text { Not sure } \\
\text { Yes }\end{array}$ \\
\hline $\begin{array}{l}\text { Would you like to play a serious game in this vir- } \\
\text { tual environment (if yes, what could be the goal } \\
\text { of the game)? }\end{array}$ & $\begin{array}{l}\text { IMP4-serious } \\
\text { game }\end{array}$ & $\begin{array}{l}\text { No } \\
\text { Maybe } \\
\text { Yes }\end{array}$ \\
\hline What you did not like in the project and why? & IMP5-flaws & $\begin{array}{l}\text { Many } \\
\text { A few } \\
\text { Only one } \\
\text { No }\end{array}$ \\
\hline $\begin{array}{l}\text { Have you felt dizzy while exploring the virtual en- } \\
\text { vironment? }\end{array}$ & IMP6-dizziness & $\begin{array}{l}\text { No } \\
\text { Yes }\end{array}$ \\
\hline
\end{tabular}


Table 4. The codes and the number of answers provided.

\begin{tabular}{|c|c|c|c|}
\hline Code & Answer & Code & Answer \\
\hline IP & $\begin{array}{l}\text { Correct (27) } \\
\text { Incorrect (13) }\end{array}$ & IN4 & Yes (8) \\
\hline IM1 & \begin{tabular}{|l} 
Long (1) \\
Good (6) \\
Short (1)
\end{tabular} & IN5 & High (8) \\
\hline IM2 & $\begin{array}{l}\text { Good (4) } \\
\text { Average (3) } \\
\text { Bad (1) }\end{array}$ & IMP1 & $\begin{array}{l}\text { Very good }(4) \\
\text { Good }(4)\end{array}$ \\
\hline $\mathrm{P} 1$ & $\begin{array}{l}\text { High (2) } \\
\text { Average (4) } \\
\text { Low (2) }\end{array}$ & IMP2 & High (8) \\
\hline P2 & $\begin{array}{l}\text { Interior (4) } \\
\text { Both (2) } \\
\text { Exterior (2) }\end{array}$ & IMP3 & $\begin{array}{l}\text { Yes }(7) \\
\text { Not sure (1) }\end{array}$ \\
\hline P3 & $\begin{array}{l}\text { Very high (3) } \\
\text { High (1) } \\
\text { Low }(2)\end{array}$ & IMP4 & $\begin{array}{l}\text { Yes (3) } \\
\text { Maybe (2) } \\
\text { No (3) }\end{array}$ \\
\hline IN1 & $\begin{array}{l}\text { Ashamed } \\
\text { Sad (3) } \\
\text { Respectful } \\
\text { Angry (2) } \\
\text { Impressed } \\
\text { Curious } \\
\text { Upset }\end{array}$ & IMP5 & $\begin{array}{l}\text { No }(1) \\
\text { Only one (5) } \\
\text { A few }(3)\end{array}$ \\
\hline IN2 & High (8) & IMP6 & No (8) \\
\hline IN3 & $\begin{array}{l}\text { High (4) } \\
\text { Average (2) } \\
\text { Low (1) }\end{array}$ & & \\
\hline
\end{tabular}

Six out of 8 participants found the length of the story as good (IM1). One participant, that found it as long enough, also added a valuable comment: "The answer would change, of course, depending on the level of interest in the topic. It might be long for someone with a very casual interest. Someone deeply interested would probably be interested in more view with more information." This is very true and should be taken into account for any future work. The length of the presentation could also affect the mood and emotions of participants. Most of them reported feeling sad and angry/upset while watching the story (IN1). Some other emotions reported are: ashamed, respectful, impressed and curious. However, regardless of the nature of the story (savage destruction of a cultural heritage object during the war in Bosnia) and negative emotions evoked, the participants generally enjoyed the interactive digital story (IN2). A few of them reported that they enjoyed the application, but not some facts from the story. The overall impression on the project was very good (IMP1). "Well done, communicating the moral message, besides the story of destruction." and "Very good project with important content and clear message." are some of the responses (IMP1) signifying the importance of the project and the conveyed information. 
The usefulness of the project was rated as high (IMP2). The users found various important aspects of the project: "it uses memory to prevent us from a similar bad fate in the future, and it uses technology to repair what was damaged and-or lost. ", "I think it helps to preserve important historical aspects.", "Project is very important for collective memory of the local community; to explain wider public possible consequences of wars", "I find it very useful to give the opportunity to "see" sites that are not existing and/or too far away to be visited" (IMP2).

However, semi-structured questionnaires allow for collecting not only the foreseen information but also some additional, unexpected data. Besides the mentioned, positive critics on the projects, some gaps of the proposed concept were identified. There were a few complaints and suggestions about the content: "Id like to see and learn more about e.g. the icons" (IM1), "I would like it to be made more clear who destroyed it" (IM1), "Id also like to know more about the churchs interiors and its symbolism and also how the church was used by the community by e.g. reproduce ceremonies and other celebrations" (IN3). Another element that was criticised is the navigation (IM2). A tree structured navigation, that would allow for easy wandering through the story, was proposed. Additionally, participants complained that they can not speed up the digital stories, and would like to have a timeline. One of the comments was: "provide alternative logical paths through the digital story, with the main (shorter) path and detailed branches from the main path clearly labeled" (IM1). All these are highly valuable comments and could be included in the next versions of the project in the future.

\subsection{Serious games application}

As several elements of serial gaming have been involved into this project, including virtual reconstruction of cultural heritage, entertainment, education, virtual guides, there is a potential for using such concept in serious games. The user responses were fairly positive regarding making a serious game in this virtual environment (IMP4). There were several propositions for a serious game:

- "Protect the pieces of the church during being damaged.";

- "Something related to the icons and the stories behind them, for beginning: Memory like games.";

- "Of course - castle defense!".

\section{Conclusions and future work}

The technologies commonly associated with computer games are not any more solely an entertainment medium. Instead, they could be a significant factor in education, medical and scientific applications and simulations, and historical presentations. In this paper we demonstrated the effectiveness and usability of live virtual guides for storytelling purposes in a virtual cultural heritage reconstruction scenario. The live virtual guides with the alpha channel were superimposed 
onto panoramic images in Flash environment. The model was then compared with the same scenario implemented with the X3D virtual environment. The Flash implementation introduced many benefits comparing to the X3D application. The main advantages were data size, download speed, offline rendering capability, better image quality, and easier navigation in the environment. The main drawback of this approach is the navigational restriction to predefined view points in the environment. This, however, might be considered as a minor issue comparing to the achieved enhancements.

The results from the first user study imply that the loading speed, dependent mostly on the data size, and the possibility to run the environment is more important than the ability to freely walk around the object. Furthermore, with the Flash environment, it is possible to add as many view points as we like, and to link them to important objects or spots. That would give more freedom and spatial width to a user while browsing the environment. Additionally, for the comparison purpose, the 3D model for the Flash implementation was rendered using almost the same scene setup as for the X3D application, in order to achieve similar appearance of the outcome. Nevertheless, the models could be rendered with higher visual quality, adjusting the geometry, lighting, material and rendering settings within Maya or similar modeling and/or rendering software. Those steps could have been directly implemented in the model creation pipeline, if the model was intended for high-fidelity rendering purposes, which, in that case, would not require any additional effort.

In the second part of the project, various elements of digital storytelling and information presentation were combined into a story guided virtual environment. This type of environment guides a user through the story about the cultural heritage object, giving him or her opportunity to explore the $3 \mathrm{D}$ virtual model and learn more from the live virtual guides. The proposed navigation allows the user to skip any part of the digital story or move on from the virtual environment to the next story. The initial user feedback, described and presented in Section 6.2 , supports the stated hypotheses. Namely, the data analysis indicates that our concept is highly effective in information conveyance in cultural heritage virtual reconstruction applications and that it could be used as a platform for edutainment. Furthermore, its presentation style is eminently enjoyable despite the topic and emotional state of participants. Finally, the concept is highly significant and useful for reviving the non-existing objects in the memory of the visitors and for attracting the potential visitors to the heritage site.

This is, to the best of our knowledge, the first attempt to combine various digital storytelling techniques in a Flash environment for cultural heritage virtual reconstruction. Therefore, it represents a further step from the traditional non-interactive narrative content in computer games: we propose the narrator as a live person and the environment to be interactive; and common interactive non-narrative presentations as seen in traditional video games. This concept could be used for creating educational serious games, such as quizzes or puzzle games, where storytelling is important aspect of the game. Additionally, it 
could be exceptionally suitable for virtual reconstructions and virtual museum applications.

In the future detailed user studies with more participants will be undertaken, comparing different concepts in terms of storytelling, interactivity, information conveyance, audio-visual quality and gameplay. We would also like to apply the same concept to some other virtual environments, with similar or different scenarios and purposes. Furthermore, it would be valuable to make a serious game using our concept and evaluate the same elements through the actual gameplay.

Acknowledgments. The authors would like to thank all the volunteers who participated in the study. In addition, we would like to thank dr Amela Karahasanovic for her valuable input on designing the qualitative user study and analysing the data.

\section{References}

1. Church of the Holy Trinity. http://crkva-sv-trojice.ba

2. Hermitage Museum. http://www.hermitage.ru

3. Louvre. http://www. louvre.fr/

4. Sarajevo Survival Tools Project. http://h.etf.unsa.ba/srp/project.htm

5. Story Guided Virtual Environment. http://crkva-sv-trojice.ba/VR-digStory/ digStory1-ENG.html

6. The Metropolitan Museum (New York). http://www.metmuseum.org/, http:// www. metmuseum.org/

7. The National Gallery (London). http://www.nationalgallery.org.uk, http:// www. nationalgallery.org.uk/

8. The Tower of Pisa. http://www.compart-multimedia.com/, http://www. compart-multimedia.com/virtuale/

9. The Uffizi (Florence). http://musa.uffizi.firenze.it/, http://musa.uffizi. firenze.it/

10. The Virtual Museum of Canada. http://www.museevirtuel-virtualmuseum.ca/, http://www.museevirtuel-virtualmuseum.ca/

11. Virtual Museum of the Sarajevo Assassination. http://h.etf.unsa.ba/ vmuzej-atentata

12. Virtual National Museum of Bosnia and Herzegovina. http://projects.etf. unsa.ba/ vmuzej/

13. National Museum of the American Indian. http://www.nmai.si.edu/ (2002)

14. Arco. http://www.arco-web.org/ (2003), http://www.arco-web.org/

15. Athena. http://www. athenaeurope.org/ (2008), http://www. athenaeurope. org/

16. Europeana. http://group.europeana.eu/ (2008), http://group.europeana.eu/

17. Digital Catalogue of Stecaks. http://h.etf.unsa.ba/dig-katalog-stecaka (2009)

18. Virtual Museum of Bosnian Traditional Objects. http://www .muzejsarajeva.ba/ (2009) 
19. Anderson, E.F., McLoughlin, L., Liarokapis, F., Peters, C., Petridis, P., de Freitas, S.: Serious games in cultural heritage. In: VAST 2009: 10th International Symposium on Virtual Reality, Archaeology and Cultural Heritage - VAST-STAR, Short and Project Proceedings. pp. 29-48. Faculty of ICT, University of Malta (2009), state-of-the-Art-Report

20. Basili, V.R., Selby, R.W., Hutchens, D.H.: Experimentation in software engineering. IEEE Trans. Softw. Eng. 12, 733-743 (July 1986), http://dl.acm.org/ citation. cfm?id=9775.9777

21. Brown, S., Ladeira, I., Winterbottom, C., Blake, E.: The effects of mediation in a storytelling virtual environment. In: In Virtual Storytelling: Using Virtual Reality Technologies for Storytelling (2003), Springer-Verlag. Proc. 2nd International Conference ICVS. pp. 102-111 (2003)

22. Debevec, P.: Making "the parthenon" (2004)

23. Earl, G.P.: Wandering the house of the birds: reconstruction and perception at roman italica. In: VAST '05: Proceedings of the 2005 conference on Virtual reality, archeology, and cultural heritage, short papers (2005)

24. Foni, A., Papagiannakis, G., Magnenat-Thalmann, N.: Virtual hagia sophia: Restitution, visualization and virtual life simulation. In: UNESCO World Heritage Congress Proceedings (October 2002)

25. Frischer, B., Abernathy, D., Guidi, G., Myers, J., Thibodeau, C., Salvemini, A., Müller, P., Hofstee, P., Minor, B.: Rome reborn. In: SIGGRAPH '08: ACM SIGGRAPH 2008 new tech demos. pp. 1-1. ACM, New York, NY, USA (2008)

26. Gaitatzes, A., Christopoulos, D., Roussou, M.: Reviving the past: cultural heritage meets virtual reality. In: VAST '01: Proceedings of the 2001 conference on Virtual reality, archeology, and cultural heritage. pp. 103-110. ACM, New York, NY, USA (2001)

27. Glaser, B., Strauss, A.: The discovery of grounded theory: Strategies for qualitative research. Aldine Publ. (1977), http://books.google.com/books?id= rtiNK68Xt08C

28. Gutierrez, D., Seron, F.J., Magallon, J.A., Sobreviela, E.J., Latorre, P.: Archaeological and cultural heritage: bringing life to an unearthed muslim suburb in an immersive environment. Journal of Cultural Heritage 5(1), $63-74$ (2004), http://www.sciencedirect.com/science/article/B6W6G-4BY308Y-7/2/ 5914a86f62db9bfe79a5c2844600f6e5

29. Habel, R.: Create your own hdr environment map in maya/mental ray for image based lighting. http://www.vi-motion.de/latlong \_Tutorial/

30. Johnson, A., Leigh, J., Carter, B., Sosnoski, J., Jones, S.: Virtual harlem. IEEE Computer Graphics and Applications 22, 61-67 (2002)

31. Karkin, Z., Rizvic, S.: Virtuelna 3d rekonstrukcija crkve svete trojice u mostaru. In: International Symposium on Digitalization of Cultural Heritage in Bosnia and Herzegovina (2008)

32. Ladeira, I., Blake, E.H.: Virtual san storytelling for children: Content vs. experience. In: VAST. pp. 223-231 (2004)

33. Lazar, J., Feng, J.H., Hochheiser, H.: Research Methods In Human-Computer Interaction. Wiley (2010), http://www.wiley.com/WileyCDA/WileyTitle/ productCd-EHEP001660.html

34. Peterson, L.R., Peterson, M.J.: Short-term memory retention of individual items. Journal of Experimental Psychology 58, 193-198 (1959)

35. Ramic-Brkic, B., Karkin, Z., Sadzak, A., Selimovic, D., Rizvic, S.: Augmented realtime virtual environment of the church of the holy trinity in mostar. In: Proceed- 
ings of the 2009 ACM/Eurographics International Symposium on Virtual Reality, Archaeology and Cultural Heritage. pp. 141-148 (2009)

36. Rizvic, S., Sadzak, A.: Digital storytelling - representation of bosnian intangible heritage in the virtual sarajevo project. In: International Symposium on Virtual Reality, Archaeology and Cultural Heritage (VAST 2008). Braga, Portugal (2008)

37. Rizvic, S., Sadzak, A., Buza, E., Chalmers, A.: Virtual reconstruction and digitalization of cultural heritage sites in bosnia and herzegovina. In: SEEDI 2007, Review of the National Center for Digitization. pp. 82-90. Faculty of Mathematics, Belgrade, Serbia (2008)

38. Sadzak, A., Rizvic, S., Chalmers, A.: The influence of storytelling quality on the human perception of computer animation. In: International Symposium on Virtual Reality, Archaeology and Cultural Heritage (VAST 2007) (2007)

39. Sadzak, A., Rizvic, S., Dalton, C., Chalmers, A.: Information perception in virtual heritage storytelling using animated and real avatars. In: Spring Conference on Computer Graphics (2007)

40. Sundstedt, V., Chalmers, A., Martinez, P.: High fidelity reconstruction of the ancient egyptian temple of kalabsha. In: AFRIGRAPH '04: Proceedings of the 3rd international conference on Computer graphics, virtual reality, visualisation and interaction in Africa. pp. 107-113. ACM, New York, NY, USA (2004)

41. Yeh, S.C., Newman, B., Liewer, M., Pair, J., Treskunov, A., Reger, G., Rothbaum, B.O., Difede, J., Spitalnick, J., McLay, R., Parsons, T.D., Rizzo, A.A.: A virtual iraq system for the treatment of combat-related posttraumatic stress disorder. In: VR. pp. 163-170 (2009) 